\title{
ANTIBACTERIAL EFFECT OF SALVADORA PERSICA ROOTS NANOPARTICLES VERSUS SODIUM HYPOCHLORITE AS ROOT CANAL IRRIGATION
}

\author{
Elsaeed Abdel Hafez * and Amgad H . Soliman *
}

\begin{abstract}
Aim: Discovering the antibacterial behavior of Salvadora persica roots Nanoparticles versus sodium hypochlorite.

Methods: 22 extracted anterior teeth adjusted for $18 \mathrm{~mm}$ length standardization. The root canals were initially prepared using manual instrumentation till size 25 for apical preparation. Sterilization of the samples was done using gamma rays. After sterilization, the samples were then divided into two groups (with $n=11$ ) according to the tested irrigating material used as follow; Group1: $2 \%$ sodium hypochlorite and Group 2: Salvadora persica roots nanoparticles. Mechanical preparation was accomplished by Revo-S system from crown to the apex. Counting of the E. Fecalis was done before and after irrigation by determining the Colony Forming Unit.
\end{abstract}

Results: The highest value of percentage changes in bacterial reduction was in Group 1 (Ninety four percentage) and the least bacterial reduction percentage was found in (Group 2) (Eighty five percentage) with no significant difference statistically between both groups.

Conclusion: Salvadora persica roots nanoparticles is a promising irrigating solution of herbal origin.

\section{INTRODUCTION}

Disinfection of root canal including get rid of microorganisms and their by-products is a big challenge to get successful root canal therapy.

Enterococcus Fecalis Bacteria (EF) is the main causative microorganisms in pulp and periapical infection ${ }^{(1,2)}$. The ridding of such microorganisms can be done by chemo-mechanical preparation ${ }^{(3)}$.
The use of natural products and medicaments has markedly increased in dentistry to overcome the side effect of the traditional irrigating solutions ${ }^{(4)}$. Salvadora persica roots is the most beneficial herbs in dentistry that has been scientifically to have strong antibacterial effect due to its active ingredients (B-sitosterol, Benzyl-isothiocyanate, Elemental sulfur, Saponin Tannic acid, Resin, Trimethylamine, Alkaloid, Chlorine, Fluoride, silica, Sodium bicarbonate, Chlorides) ${ }^{(5,6)}$.

\footnotetext{
* Lecturer of Endodontics, Faculty of Oral and Dental Medicine ,Future University- Egypt.
} 
Introduction of nanotechnology has been improving the bactericidal effect in addition to the physical and chemical properties of the irrigating materials, the nanotechnology converting their solid forms to the smallest nanoparticles ${ }^{(7)}$. Additionally, nanoparticles powder of Salvadora persica roots achieves the maximum solubility of its active ingredients increasing its bactericidal effect ${ }^{(8)}$. But little researches have been established to evaluate the antibacterial effect of Salvadora persica roots versus sodium hypochlorite irrigating solution.

\section{MATERIALS AND METHOD:}

\section{Preparation of the samples}

Twenty two extracted anterior teeth with root curvature ranged from $0-25$ degree according to schlider technique ${ }^{(9)}$ were selected in this study. Following preoperative radiographic examination of the collected teeth to exclude any tooth abnormalities, such as pulp stones or teeth with root cracks and/or fractures, the root of the selected teeth were planned with an ultrasonic scaler (Suprasson P5 Booster, Satelec, France) to remove any hard deposits and soft tissue remnants on the root. Decapitation of the selected teeth for $18 \mathrm{~mm}$ length standardization using a diamond cylindrical stone with a high speed handpiece (PANA AIR, NSK, Japan) under water coolant was done. The samples were kept in saline at room temperature till use. A size $15 \mathrm{~K}$ file (Dentsply, Maillefer, Ballaigues, Switzerland) was used to check patency and working length determination. The canals were initially prepared using manual instrumentation till size 25 for apical preparation.

\section{Isolation and growing of the Enterococcus Feca- lis Bacteria (EF)}

Facultative E. Fecalis Bacteria (EFB) was collected for isolation of EFB using brain heart infusion medium. This is followed by growing of EFB colonies in $100 \mathrm{ml}$ nutrient broth media in sterile glass flask capped with cotton plug.
The glass flask containing bacteria was preserved in an incubator (Incubator in 08877433 Made in Italy) for 72 hours to allow for bacterial growth.

\section{Colonization of the EF in the samples}

Following serialization of the samples using gamma rays (Egyptian Atomic Energy Authority), the colonized E. Fecalis bacteria were carried to the sterile samples using microbiological micropipette to carry three micron of the liquid that contain $\mathrm{EF}$ bacteria in nutrient broth media for colonization of the E. Fecalis bacteria in the samples. Three microns of the suspension containing E. Fecalis was injected into each sample using the microbiological micropipette with sterile disposable plastic tip for each sample. Refreshing the canal of each sample with nutrient broth media every 2-3 days was done to allow for bacterial growth.

\section{Pre-irrigation counting of the colonized bacteria}

After 2 weeks of bacterial colonization inside the samples, a previously sterile plastic standard dandruff tube was used to carry the suspension containing E. Fecalis from inside the root canal of each sample. Bacterial counting was done to determine the pre-irrigation counting of E. Fecalis using standard, viable, plate counting method for counting the viable EFB by determining the Colony Forming Unit.

\section{Grouping of the samples}

The tested samples were divided to make two groups (11 samples for each group) according to the tested irrigating solution used as follow; Group 1: the Samples were irrigated by two percentage sodium hypochlorite (Prime Dental Products, Pvt. Ltd. India) irrigating solution, and Group 2: Samples irrigation using Salvadora persica roots nanoparticles.

\section{Preparation of Salvadora persica roots nanoparticles}

The previously collected small sticks of Salvadora Persica roots ${ }^{*} \mathrm{~F}$ (Arrack tree roots, Miswak) were 
sun dried for 10 days. The dried Salvadora Persica roots were cut to small pieces and were grounded to the smallest particle powder (Nano particles less than 1 micron) using milling machine (Photon Nano milling machine, Germany). The prepared Nano particles powder of Salvadora Persica roots was kept sterile and tightly packed bottles to be used.

One hundred gram of the previously prepared Nano particles powder of Salvadora Persica roots was mixed with two hundred $\mathrm{ml}$ distilled water and was shacked well for preparation of the aqueous solution of Salvadora Persica Nano particles. This solution was kept in sterile, tightly sealed, glass bottle till time of paste preparation.

\section{Chemo-mechanical preparation of the samples}

The root canals were instrumented using Revo-S (Micro-Mega, France) rotary system for a crown down technique using the file sequence tell size AS40 as a master apical file.The Revo-S files were mounted on a contra angle handpiece that was attached to a torque-limiting motor (Dentsply Maillefer, Ballaigues, Switzerland) at a speed of $300 \mathrm{RPM}$ and torque $0.8 \mathrm{Ncm}$. Irrigation of the root canals was done between subsequent files using $2 \mathrm{ml}$ of the tested irrigating solutions according to each group .The tesed irrigating solution was delivered into the root canals using 27 gauge needle tip, 25 $\mathrm{mm}$ in length that was attached to the Max- I- probe irrigating syringe (DENTSPLY Maillefer, USA).

\section{Post-irrigation counting of Enterococcus Fecalis Bacteria}

The post-irrigation counting of the viable bacterial colonies of EF was done using the same technique and restrictions for pre-irrigation counting of bacteria using standard, viable, plate counting method for counting the viable EFB by determining the Colony Forming Unit (CFU).

\section{Statistical analysis of the data}

The mean and standard deviation values were calculated for each group. Data were explored for normality using Kolmogorov-Smirnov and Shapiro-Wilk tests and showed parametric (normal) distribution. Independent sample t-test was used to test the difference between two non-related samples. Paired sample t-test was used to test the difference between two related samples. The significance level was set at $\mathrm{P} \leq 0.05$.

\section{RESULTS}

The mean values, standard deviation, P-values, and the mean percentage changes in bacterial reduction when comparing between Group 1 and Group 2 before and after bacterial reduction was presented in Fig. (1,2), and Table (1).

The results of pre-irrigation bacterial counting of both groups showed the highest mean value of bacterial count in Salvadora persica irrigation group (Group 2) $\left(25.72 \times 10^{4} \pm 15.67 \times 10^{4}\right)$ while the least mean value of bacterial count was found in sodium hypochlorite irrigation group (Group 1) $\left(23.61 \times 10^{4}\right.$ $\left.\pm 4.23 \times 10^{4}\right)$ with no significant difference between the groups ( $\mathrm{P}$ Value $=0.534$ ).

The results of post-irrigation bacterial counting of both groups showed the highest mean value of bacterial count in Salvadora persica irrigation group $\left(5.23 \times 10^{4} \pm 3.99 \times 10^{4}\right)$ while the least mean value of bacterial count was found in sodium hypochlorite irrigation group $\left(1 \times 10^{4} \pm 0.99 \times 10^{4}\right)$ with no significant difference between the groups $(\mathrm{P}$ value $=0.065)$.

On other hand there was a significant difference between pre irrigation and post irrigation bacterial counting In Group $1(\mathrm{P}=0.001)$, and In Group 2 $(\mathrm{p}=0.002)$.

The highest mean value of percentage changes in bacterial reduction was found in (Group 1) $(94 \%)$ and the least bacterial reduction percentage was found in (Group 2) (85\% with no significant difference between the groups $(\mathrm{P}-\mathrm{value}=0.055)$.

\footnotetext{
* Collected from Makah Al-mokaramah, KSA.
} 
TABLE (1) the mean values, standard deviation, P-values, and the mean $\%$ changes in bacterial reduction when comparing between group 1 and Group 2 before and after bacterial reduction.

\begin{tabular}{|c|c|c|c|c|c|c|}
\hline \multirow{2}{*}{ Variables } & \multicolumn{2}{|c|}{ Pre irrigation count } & \multicolumn{2}{c|}{ Post irrigation count } & \multirow{2}{*}{$\begin{array}{c}\text { Mean percentage } \\
\text { changes in bacterial } \\
\text { reduction }\end{array}$} \\
\cline { 2 - 7 } & Mean & SD & Mean & SD & $0.001^{*}$ & $94 \%^{\mathrm{c}}$ \\
\hline Group 1 & $23.61 \times 10^{4 \mathrm{a}}$ & $4.23 \times 10^{4}$ & $1 \times 10^{4 \mathrm{~b}}$ & $0.99 \times 10^{4}$ & $0.002^{*}$ & $85 \%^{\mathrm{c}}$ \\
\hline Group 2 & $25.72 \times 10^{4 \mathrm{a}}$ & $15.67 \times 10^{4}$ & $5.23 \times 10^{4 \mathrm{~b}}$ & $3.99 \times 10^{4}$ & $0.055 \mathrm{~ns}$ \\
\hline
\end{tabular}

*; significant (p<0.05) ns; non-significant (p>0.05).

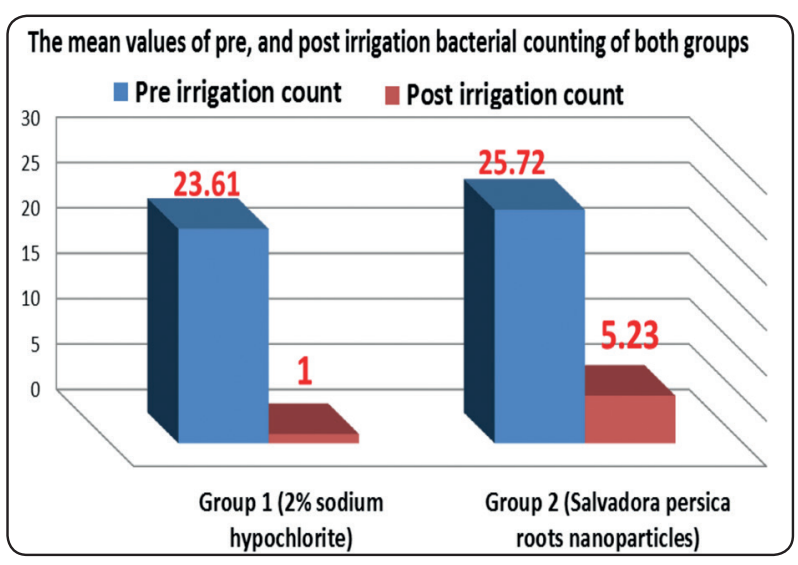

Fig. (1) Histogram showing the mean differences of bacterial count in the test groups.

\section{DISCUSSION}

Using the nanoparticles as antimicrobial has attracted a great attention in dentistry as a result of their antibacterial properties compared with those of other antimicrobial agents ${ }^{(10)}$. The antimicrobial properties of nanoparticles against on different microorganisms differ from the original bulk state and may vary according to the different types of nanoparticles ${ }^{(11)}$.

There is a great effect of the use of different types of nanoparticles as antimicrobial especially against E. faecalis $^{(12)}$.

E. faecalis is bacterial species that can persist in treated canals and are resistant to traditional

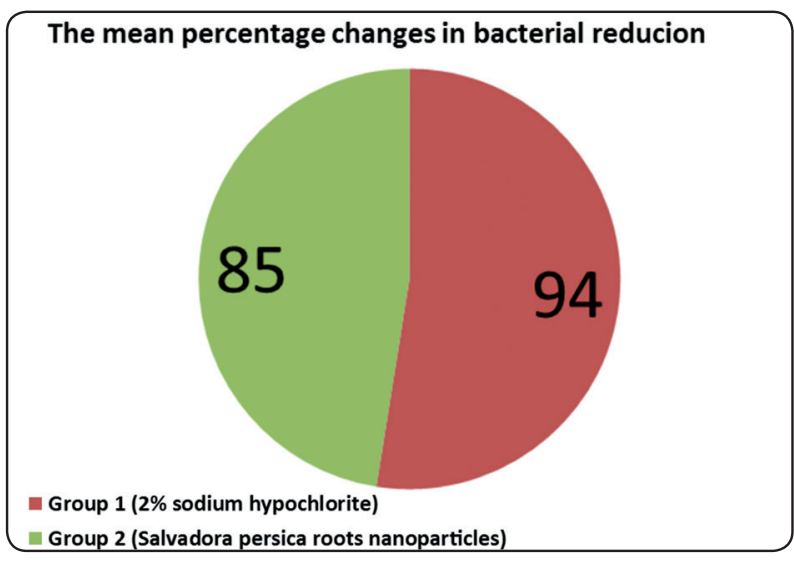

Fig. (2) Histogram showing the percentage changes in bacterial reduction in both groups.

antibacterial materials ${ }^{(13)}$. The antibacterial activity was directly related to the concentration of the test solutions ${ }^{(14)}$.

The irrigating solution should have a maximum antimicrobial action with low toxicity, physical and chemical properties ${ }^{(15)}$. The major advantages of using herbal alternatives are easy availability, low cost, increased shelf life, low toxicity, and lack of microbial resistance ${ }^{(16)}$.

The present study was aimed to discover the antibacterial behavior of Salvadora persica roots Nanoparticles versus sodium hypochlorite.

The results of our study illustrated that the highest mean value of percentage changes in 
bacterial reduction was found in Group1 (2\% sodium hypochlorite) by $94 \%$ and the least bacterial reduction percentage was found in Group2 (Salvadora persica roots nanoparticles) by $85 \%$ with no difference between the groups $(\mathrm{P}-\mathrm{value}=0.055)$.

The reason of these results may be due to Salvadora persica extracts glycosides, sterols, terpenes, flavonoids, tannins and alkaloids. The antimicrobial activity of herbal plant may be related to these constituents ${ }^{(17)}$.

Farooqi et al. isolated benzyl-isothiocyanate from Salvadora persica root, and they claimed to have found saponins along with tannins, silica, a small amount of resin, tri methylamine, and alkaloidal constituents. On other side Ray et al. isolated $\beta$-sitosterol, $\mathrm{m}$-anisic acid, and salvadourea. Other authors reported a high content of minerals in salvadourea ${ }^{(18)}$.

Anther researchers isolated the active ingredient from Salvadora persica, and they found that the limonoid had a great antimicrobial activity against various microorganisms ${ }^{(19)}$.

The results of this study are similar to the results of other studies that proved the antimicrobial behavior of Salvadora persica. An author reported antimicrobial effect at $15 \%$ alcoholic Miswak extract; however, this was not significantly different from sodium hypochlorite ${ }^{(20)}$.

Anther researcher reported that Miswak extract had an antibacterial activity against Streptococcus faecalis, Pseudomonas aeruginosa, and Staphylococcus aureus, due to its nitrate content ${ }^{(21)}$.

On other hand Salvadorapersica were investigated for its antimicrobial activities. The aqueous extract inhibited all isolated microorganisms more efficient than the methanol extract ${ }^{(22)}$.

In other study revealed that Salvadora persica is an effective antimicrobial agent when used as an irrigant in teeth with necrotic pulps ${ }^{(23)}$.

\section{CONCLUSIONS}

Salvadora persica roots nanoparticles is a promising irrigating solution of herbal origin.

\section{REFERENCES}

1- Gomes B, Pinheiro E. Enterococcus faecalis in dental root canals detected by culture and by polymerase chain reaction analysis. Radiol Endod j. 2006; 102:247-53.

2- Shingare P, Chaugule V. Comparative evaluation of antimicrobial activity of Miswak Propolis, Sodium hypochlorite and saline as root canal irrigants by microbial culturing and quantification in chronically exposed primary teeth .GERMS 2011; 1:12-21.

3- Vianna M,Gomes B. In vitro evaluation of the susceptibility of endodontic pathogens to calcium hydroxide combined with different vehicles. Braz Dent J 2005; 16:175-80.

4- Coates A, HuY, Bax Ret al. The future challenges facing the development of new antimicrobial drugs. Nat Rev Drug Discov 2002; 1: 895-901.

5- Darout, Christy A, Skaug N, Egeberg P. Identification and quantification of some potentially antimicrobial anionic components in miswak extract. Indian J Pharmacol.2000; 32:11-14

6- Sarougekasi, christy. Identification and Quantification of some potentially Anionic Components in Miswak. Ghazanfar SA 2007; 32: 11.

7- Akaptta, Es. Effects of endodontic procedures on the population of viable microorganisms in the infected root canal. J Endod. 1976; 2:369-73.

8- Margarida Coelho Abrantes3, Carrilho, Effect of calcium hydroxide as intracanal medication on the apical sealing ability of mineral trioxide aggregate (MTA). Scand J Dent Res. 1981; 89:321-8.

9- Schneider S.W. A comparison of canal preparations in straight and curved root canals. Oral Surg Oral Med Oral Pathol 1971; 32: p. 271-5.

10- Seil JT, Webster TJ. Antimicrobial applications of nanotechnology: methods and literature. International Journal of Nano medicine 2012; 7:2767.

11- Beyth N, Houri-Haddad Y, Domb A, Khan W, Hazan R. Alternative antimicrobial approach: nano-antimicrobial materials. Evidence-Based Complementary and Alternative Medicine 2015; 2015:1-16. 
12- Ibrahim A I O, Moodley D S, Petrik L, Patel N. Use of antibacterial nanoparticles in endodontics. SADJ April $2017 ; 72$; (3) 105 - 112.

13- Pinheiro ET, Gomes BP, Ferraz CC, et al. Microorganisms from canals of root-filled teeth with periapical lesions. Int Endod J 2003; 36:1-11.

14- Prabhakar J, Senthilkumar M, Priya M.S, Mahalakshmi K, Sehgal P.K, Sukumaran V.G. Evaluation of Antimicrobial Efficacy of Herbal Alternatives (Triphala and Green Tea Polyphenols), MTAD, and 5\% Sodium Hypochlorite against Enterococcus faecalis Biofilm Formed on Tooth Substrate: An In Vitro Study. J Endod. ; 36; 1:2010.

15- Ferreira CM, Bonifacio KC, Froner IC, Ito IY. Evaluation of the antimicrobial activity of three irrigating solutions in teeth with pulpal necrosis. Braz Dent J. 1999; 10(1): 15-21.

16- Abascal K, Yarnell E. Herbs and drug resistance. Part 2-clinical implications of research on microbial resistance to antibiotics. Altern Complementary Therapies 2002; 8:284-90.

17- Anthoney Swamy T, Lasiti T. Timothy Phytochemical and antibacterial evaluation of ethanolic extract of Salvadora persica root extract against selected microorganisms. International Journal of Bioassays 4.12 (2015): 4658- 66.
18- Khatak M, Khatak S , Siddqui A.A, Vasudeva N, Aggarwal A, Aggarwal P. Salvadora persica. Pharmacognosy Reviews 2010;4 (8):209- 14.

19- Wolinsky LE, Sote EO. Isolation of natural plaque inhibiting substances from Nigerian chewing sticks. Caries Res. 1984; 18: 216-225.

20- Al-Sabawi NAK, Al Sheikh Abdal AKK, Taha MY. The antimicrobial activity of Salvadora Persica solution (Miswak- Siwak) as root canal irrigant (A comparative study). University of Sharjah Journal of Pure \& Applied Sciences 2007; 4: 69- 91.

21- Darout IA, Christy AA, Skaug N, Egeberg PK. Identification and quantification of some potentially antimicrobial anionic components in Miswak extract. Indian J Pharmacol 2000; 32: 11-14.

22- Firas A., AL-Bayati, D. Khudir and Sulaiman. In vitro antimicrobial activity of salvadora persica L. extracts against some isolated oral pathogens in Iraq. Turk. J. Biol., 2008; 32: 57-62.

23- Al- Salman TH, Al- Shaekh Ali MGh, Al- Nu'aimy OM. The antimicrobial effect of water extraction of Salvadora persica (Miswak) as a root canal irrigant. Al-Rafidain Dent J. 2005; 5(1): 33-36. 